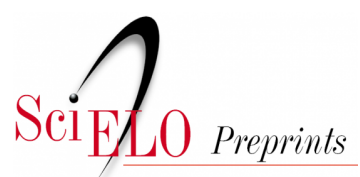

Situação: O preprint foi submetido para publicação em um periódico

\section{A equidade em situações-limite: acesso ao tratamento para pessoas com hemofilia}

Andréa Carolina Lins de Góis, Daniela Amado Rabelo, Tiago Félix Marques, Natan Monsores

DOI: 10.1590/SciELOPreprints.1361

Este preprint foi submetido sob as seguintes condições:

- O autor submissor declara que todos os autores responsáveis pela elaboração do manuscrito concordam com este depósito.

- Os autores declaram que estão cientes que são os únicos responsáveis pelo conteúdo do preprint e que o depósito no SciELO Preprints não significa nenhum compromisso de parte do SciELO, exceto sua preservação e disseminação.

- Os autores declaram que a pesquisa que deu origem ao manuscrito seguiu as boas práticas éticas e que as necessárias aprovações de comitês de ética de pesquisa estão descritas no manuscrito, quando aplicável.

- Os autores declaram que os necessários Termos de Consentimento Livre e Esclarecido de participantes ou pacientes na pesquisa foram obtidos e estão descritos no manuscrito, quando aplicável.

- Os autores declaram que a elaboração do manuscrito seguiu as normas éticas de comunicação científica.

- Os autores declaram que o manuscrito não foi depositado e/ou disponibilizado previamente em outro servidor de preprints.

- Os autores declaram que no caso deste manuscrito ter sido submetido previamente a um periódico e estando o mesmo em avaliação receberam consentimento do periódico para realizar o depósito no servidor SciELO Preprints.

- O autor submissor declara que as contribuições de todos os autores estão incluídas no manuscrito.

- O manuscrito depositado está no formato PDF.

- Os autores declaram que caso o manuscrito venha a ser postado no servidor SciELO Preprints, o mesmo estará disponível sob licença Creative Commons CC-BY.

- Caso o manuscrito esteja em processo de revisão e publicação por um periódico, os autores declaram que receberam autorização do periódico para realizar este depósito. 


\section{A equidade em situações-limite: acesso ao tratamento para pessoas com hemofilia}

Andrea Carolina Lins de Góis ${ }^{1}$, Daniela Amado Rabelo², Tiago Félix Marques ${ }^{3}$, Natan Monsores de Sá ${ }^{4}$

\section{Resumo}

Hemofilia é uma condição hematológica rara e seu tratamento é alvo de inovação terapêutica. No encontro entre necessidades do paciente, condutas do clínico e orientação do gestor de saúde, surge o conflito: o protocolo é um mínimo ou um máximo terapêutico? As decisões clínicas em debate com a alocação de recursos levam à discussão sobre equidade nestas situações-limite. O método do presente estudo é compreensivo, mediante análise bioética de 14 decisões judiciais acerca do acesso a tratamentos para hemofilia. As decisões de garantia de acesso aos tratamentos pressupõem vinculação ética com o paciente; a clínica conserva uma dimensão de equidade ao permitir que o tratamento seja singular e as doses previstas em protocolo sejam sugestões e não limites. Do ponto de vista ético, estas são expressões de justiça, de precaução e de consideração dos interesses do paciente.

Palavras-chave: Hemofilia. Bioética. Equidade.

\section{Resumen}

\section{Equidad en situaciones-límite: acceso al tratamiento para personas con hemofilia}

La hemofilia es una enfermedad hematológica poco frecuente y su tratamiento es um objetivo de la innovación terapéutica. En el encuentro entre las necesidades del paciente, la conducta del clínico y la orientación del gestor de salud, surge el conflicto: ¿el protocuello es mínimo o máximo terapéutico? Las decisiones clínicas en debate con la asignación de recursos conducen a la discusión sobre la equidad en estas situaciones-límite. El método del presente estudio es integral, basado en el análisis bioético de 14 decisiones judiciales sobre el acceso al tratamientos de la hemofilia. Las decisiones para garantizar el acceso a los tratamientos presuponen un vínculo ético con el paciente; la clínica mantiene una dimensión de equidad, permitiendo que el tratamiento sea singular y las dosis previstas en el protocolo sean sugerencias y no límites. Desde un punto de vista ético, son expresiones de justicia, precaución y consideración de los intereses del paciente.

Palabras clave: Hemofilia. Bioética. Equidad.

\section{Abstract \\ Equity in edge situations: access to treatment for people with hemophilia}

Hemophilia is a rare hematological condition, and its treatment is a target of therapeutic innovation. In the encounter between the patient's needs, the clinician's behavior and the health manager's orientation, the conflict arises: is the clinical protocol a minimum or maximum? The clinical decisions in debate with the allocation of resources lead to the discussion about equity in these edge situations. The method of the present study is comprehensive, based on bioethical analysis of 14 court decisions regarding access to hemophilia treatments. Decisions to guarantee access to treatments presuppose an ethical link with the patient; the clinic maintains a dimension of equity allowing that treatment be singular, and the doses provided for in the protocol are suggestions and not limits. From an ethical point of view, these are expressions of justice, precaution, and consider the patient's interests.

Keywords: Hemophilia. Bioethics. Equity.

\footnotetext{
1. Mestre - andreaclgois@gmail.com - Programa de Pós-Graduação em Bioética, Faculdade de Ciências da Saúde, Universidade de Brasília (UnB). http://orcid.org/0000-0002-4482-834X

2. Mestre - daniela.a.rabelo@gmail.com - Programa de Pós-Graduação em Bioética, Faculdade de Ciências da Saúde, Universidade de Brasília (UnB). http://orcid.org/0000-0003-3725-0858

3. Mestre - twoalief@gmail.com - Programa de Pós-Graduação em Bioética, Faculdade de Ciências da Saúde, Universidade de Brasília (UnB) - Secretaria de Estado de Educação do Distrito Federal (SEE-DF), Brasil. http://orcid.org/0000-0001-5373-3812

4. Doutor - monsores@unb.br - Observatório de Doenças Raras - Programa de Pós-Graduação em Bioética, Faculdade de Ciências da Saúde, Universidade de Brasília (UnB), Brasília/DF, Brasil. https://orcid.org/0000-0002-0293-8460
}

Correspondência: Natan Monsores de Sá - Observatório de Doenças Raras - Programa de Pós-graduação em Bioética. Sala AC111. Faculdade de Ciências da Saúde. Universidade de Brasília. Brasília/DF, Brasil. CEP 70910-900.

Participação dos autores: Todos os autores participaram da concepção, redação e revisão do artigo.

Declaram não haver conflito de interesse.

Agradecemos a Capes pela concessão de apoio para realização da pesquisa. 
Introdução

A hemofilia é uma condição genética, crônica e rara, caracterizada por alteração no sistema de coagulação do sangue que gera um permanente risco de hemorragia espontânea ${ }^{1}$. $O$ tratamento se dá pela reposição de fator de coagulação (FC VIII ou FC IX), a fim de evitar sangramentos que, cumulativamente, causam sequelas e afetam a as atividades diárias e a qualidade de vida das pessoas afetadas ${ }^{2}$. A chance de ocorrerem sangramentos graves ou em órgãos vitais torna a vigilância permanente. O cotidiano é marcado pela permanente recomendação de observar certos "limites físicos" em nome da integridade física, impelindo a adoção de um conjunto de técnicas corporais restritivas, estratégias de alerta (a "aura" da hemorragia) e rituais de autocuida$\mathrm{do}^{3,4}$.

As pessoas com doenças raras, como a hemofilia, relatam longos itinerários terapêuticos ${ }^{5}$. A jornada do adoecimento estabelece, a seus andarilhos, linguajar e condutas próprios; gera expectativas sobre as formas de vida de quem é diagnosticado; prescreve comportamentos; estabelece seus códigos e jurisdição específicos; cria comunidades de iguais que buscam, na troca de seu sentipensar e de suas experiências, um bem viver ${ }^{6}$. A vida de uma pessoa com hemofilia (PCH) é atravessada por histórias familiares de sofrimento, estigma e injustiça social ${ }^{7,8}$. Seringas, agulhas, crioprecipitado, inibidores, entre tantos procedimentos e artefatos técnicos, se convertem-se numa liturgia diária ou semanal de aplicação de fator que garante não sangrar ${ }^{9}$.

Ao longo das últimas décadas, o tratamento da hemofilia variou de transfusões totais de sangue, reposição de FC até a possibilidade recente de terapia gênica ${ }^{10}$. A tendência de incorporar inovações terapêuticas e as mudanças nos protocolos clínicos para a atenção integral à saúde da PCH oferecem um registro histórico e sociotécnico peculiar, o que permite acompanhar parte da revolução biotecnológica em saúde, bem como fornecem um panorama da relação entre os movimentos sociais pelo direito à saúde e a Biotecnociência.

Os aspectos simbólicos da hemofilia (a relação com o sangue) e as questões concretas de viver com uma condição hematológica rara remetem a necessidade de sentipensar (articular raciocínio e sentimentos) o adoecimento, uma vez que este é um aspecto importante e singular da vida humana. Pôr em interação razão e emoção pode ajudar a lidar com o diagnóstico e a elaboração da própria condição, o que por vezes implica em estar situado num lugar existencial solitário. Uma abordagem sentipensante pode proporcionar condições para que a pessoa consiga dar significado aos processos que reconfiguram seu corpo, produzem experiências e memórias, modificam comportamentos e transformam dinâmicas sociais ${ }^{12}$. Sentipensar o diagnóstico situa a pessoa entre a percepção individual da dor e da alteração no corpo, passando pelo crivo da determinação objetiva da natureza da lesão, do prognóstico e da terapêutica. Este processo é perpassado por apreensões subjetivas e intersubjetivas da enfermidade, seja pelo corpo individual ou pelo social, com boas introduções ao tema ${ }^{12,13,3}$. Nosso recorte temático se refere à hemofilia e às doenças raras, um conjunto diverso de condições que têm ganhado destaque pela complexidade temática ${ }^{14,15}$.

No caso da hemofilia, a raridade e os modelos vigentes de cuidados de saúde reforçam a necessidade de compreender como a pluralidade de respostas orgânicas, percepções, pensamentos, sentimentos, sensações e emoções nos espaços de interface entre cuidador/cuidado tornam este processo um evento para o qual nem 
sempre é possível uma descrição objetiva. As questões bioéticas concernentes ao acesso às tecnologias de cuidado para hemofilia reforçam o aspecto conceitual de fronteira - trata-se de um "boundary object" - que pode ser sentipensado. A proposta do presente artigo é aplicar essa concepção de sentipensar na análise da seguinte questão bioética: a da equidade em situações-limite, particularmente, sobre a questão do acesso singular a tratamento medicamentoso preventivo para pessoas com hemofilia.

É importante entender que a reposição profilática de FC é o "standard of care" para a pessoa com hemofilia ${ }^{16}$. Segundo alguns pesquisadores, "os atuais regimes de profilaxia de dose fixa com base no peso são eficazes; no entanto, eles não têm flexibilidade e geralmente falham em atender às necessidades e expectativas individuais dos pacientes" e desenvolvimentos recentes no tratamento da hemofilia oferecem novas oportunidades para uma profilaxia mais personalizada" ${ }^{17}$. Os avanços biotecnológicos têm permitido a substituição dos hemoderivados por medicamentos biológicos. Mas sua incorporação em sistemas de saúde requer o estabelecimento de protocolos padronizados, cujo alvo é o "paciente-médio", um ente estatístico derivado de medidas epidemiológicas das formas de tratamento.

Os tratamentos para hemofilia têm sido dispensados para este "paciente-médio hipotético", o que permite planejamento e adequação da logística de aquisição/distribuição de medicamentos e ordenamento financeiro por parte do gestor do sistema de saúde. Mas, no espaço clínico, este quadro se confronta com a lógica de administração individualizada de medicamento. A customização do tratamento responde à necessidade direta do paciente. A estimativa de dose per capta de medicamento se liga às lógicas de gestão, implicadas nas relações entre Estado e Mercado. Nesse contexto, ao menos três perspectivas são postas a interagir: a orientação do gestor do sistema de saúde, a conduta do clínico e a necessidade do paciente. E assim se conforma uma situação-limite: se o protocolo é um máximo ou um mínimo terapêutico.

\section{Método}

A bioética é uma ética da vida e da saúde, e se ocupa da "vida moral como é praticada, não (apenas) como é teorizada"18. Enquanto ética aplicada, busca a resolução de problemas práticos nos campos biomédico, biotecnológico, sanitário, social e ambiental, sejam situações persistentes ou emergentes, por meio da consideração dos elementos que compõem uma situação de conflito e mediante análise de pressupostos e desdobramentos do processo de tomada de decisão naquela situação. E há muita discussão na literatura acerca de qual seria a vocação metodológica da bioética ${ }^{19-25}$. Na presente pesquisa tentaremos harmonizar pressupostos de uma bioética empírica com correntes de pensamento trabalhadas na Cátedra Unesco de Bioética da UnB.

São três as dimensões que precisam ser alcançadas no processo de pesquisa em bioética ${ }^{18}$ :

(a) A condição verídica: o processo de pesquisa deve tentar garantir que a questão ética sendo pesquisada seja genuína e autêntica, enquadrada em termos da maneira como é vivida e negociada na prática por atores morais, em vez de construída em abstrato por um teórico moral. 
(b) A condição realista: o processo de pesquisa deve tentar garantir que a análise atenda às circunstâncias nas quais os atores morais se encontram e presta a devida consideração a fatores que podem restringir ou limitar as ações ou escolhas disponíveis para os atores.

(c) A condição pragmática: o processo de pesquisa deve tentar gerar conclusões e/ou soluções para os problemas normativos que sejam suficientemente respeitosas e que envolvam as preocupações e questões das partes interessadas, de forma que possam ser aceitas e implementadas.

A abordagem metodológica que aqui se propõe é socialmente situada e compreensiva, trazendo conhecimentos, elementos, percepções e asserções, com base na proximidade e vivência do fenômeno sentipensado. Trata-se de uma análise bioética de situação (não puramente casuística/comparativa ou detida em objeções de consciência ou conflitos morais particulares ${ }^{26}$ ), na qual são ponderadas as multidimensões da situação de conflito, resguardando um esforço de harmonização entre ontologias, epistemologias e frameworks teóri$\cos ^{18}$.

O primeiro passo do processo se refere a identificação da natureza do problema bioético (se emergente ou persistente ${ }^{27}$ ), isto é, a observação sentipensante da situação que se põe para análise . Nesse instante, assume-se que o conflito de interesses existe e faz sentido, isto é, que existe um conflito moral e pode ser descrito e para o qual são possíveis respostas ou proposições (no caso de dilemas). Nesta etapa é necessário se descrever o contexto da questão moral posta em evidência, com a verificação da realidade (complexa e concreta ${ }^{28}$ ) e dos indicadores (sociais, sanitários, epidemiológicos, etc.) disponíveis.

O processo de pesquisa respeitou o fato de que as discussões em bioética têm caráter interdisciplinar. Assim estabelecemos que os elementos que compõem a questão ética a ser investigada também são atravessados por esta característica, isto é, são objetos de fronteira. O tópico escolhido, na presente pesquisa, foi o acesso a tratamento para hemofilia. Os descritores relativos à bioética são: (a) numa dimensão macrobioética - responsabilidade social e justiça em saúde; e, (b) numa dimensão microbioética - vulnerabilidade, justiça (como "fairness", assumindo-se certa dimensão intraduzível desta palavra, que corriqueiramente tem sido entendida como equidade), regra do resgate e princípio do não-abandono. Buscou-se também, de forma concatenada, os termos hemofilia, profilaxia, tratamento e bioética, em inglês e português, nas bases MEDLINE e SCIELO.

Esta etapa possui uma dimensão narrativa, no qual se pode fazer oitiva de pessoas, grupos, instituições e até mesmo objetos ou artefatos que possuam agência no mundo. Manchola enumera caminhos para que a coleta da narrativa se proceda 29,30 , e apresenta uma perspectiva que é adotada no presente trabalho, a partir dos textos de Nussbaum:

"Nussbaum ha destacado en varias de sus obras que los elementos narrativos, en algunos momentos generados por el método socrático, pueden enriquecer el juicio moral, al producir en los actores que deciden emociones como la empatía y la compasión. Según la autora, estos elementos pueden redundar en decisiones morales más ricas, en las que se tomen en consideración los diversos matices que las historias - contrario a los simples casos o relatos - incluyen, entre otros: escenarios, tiempos, personajes, tradiciones, sentimientos, valores y principios diversos." 31 
A fim de captar outras vozes envolvidas na questão dos conflitos no acesso ao tratamento de hemofilia, e entendendo que esse tema envolve o processo de tomada de decisão, em âmbitos da saúde que transcendem a clínica, foi necessário pesquisar em instituições voltadas a esta finalidade. Buscamos outro espaço em que o conflito é aparente: o Poder Judiciário. Coletamos decisões dos tribunais locais e superiores, numa inicial análise dos processos presentes no sistema judicial (NATJUS), a partir de documentos disponíveis nos próprios sítios eletrônicos das instituições. Elencamos a Portaria 725/2018/SES-DF ${ }^{32}$ como um ponto de partida normativo. Foi realizada uma pesquisa jurisprudencial na base de dados do Tribunal de Justiça do Distrito Federal e dos Territórios (TJDFT) e no Tribunal Regional Federal da 1ạ Região (TRF1) - circunscrição do DF -, sem inclusão das bases de dados dos Tribunais Superiores, com uso das palavras-chave hemofilia, medicamento, medicação e fornecimento. Foram excluídos os temas penais e previdenciários.

O segundo passo da análise corresponde ao sentipensar as possíveis respostas ou proposições a serem apresentadas para dirimir o conflito ético. Sentipensamento é um termo coletado da sabedoria popular colombiana, pelo sociólogo Borda ${ }^{33}$ e por Galeano ${ }^{34}$, sendo repercutido por Santos ${ }^{35}$, Moraes \& Torre ${ }^{36}$ :

"Na cultura do Caribe colombiano, e mais especificamente na cultura ribeirinha do rio Grande de La Magdalena, que transporta suas águas até o Oceano Atlântico, o homem-tartaruga que sabe ser aguentador para enfrentar reveses na vida e para superá-los, que na adversidade se recolhe para em seguida voltar à existência com a mesma energia de antes, é também o homem Sentipensante que combina razão e amor, corpo e coração, para se livrar de todas as (más) formações que quebram essa harmonia e para dizer a verdade, tal qual descreve Eduardo Galeano no Livro dos Abraços, em homenagem aos pescadores da costa colombiana." ${ }^{33}$

Trata-se, portanto, da integração de sentir-pensar-agir: um processo cognitivo-emocional incorporado, que está em forte contraste com o desprendimento desencarnado e abstrato do racionalismo cartesiano. De certa forma, é um fortuito encontro entre a sabedoria popular e a neurociência, pondo em evidência que diferentes epistemologias, em certas circunstâncias, podem coexistir e dialogar. Trata-se de revisitar as narrativas e de fazer um exercício de compreensão da natureza dos argumentos dos diferentes agentes, atentando-se para quais normas, virtudes, princípios e valores foram evocados no processo. Damásio, por exemplo, afirma que "Não somos máquinas de pensar, somos máquinas de sentir que pensam"37. Estes pensamentos encontram ecos em textos de outros autores ${ }^{38,30,39}$.

Nesta etapa, os aspectos simbólicos, técnicos, políticos, econômicos, históricos e sociais podem se tornar vetores de análise, por constituírem o contexto complexo e concreto no qual se dá o conflito moral. Neste momento, é possível evocar instrumentos, normativas e teorias, como por exemplo a Declaração Universal sobre Bioética e Direitos Humanos, para auxiliar na organização de uma possível resposta ao conflito. E neste processo, não se deve desconsiderar aspectos subjetivos do conflito que podem afetar os envolvidos, como por exemplo, sentimento de injustiça ou de temor ou de abandono ou de inconformismo com a situaçãoproblema. Isto é, não se assume a falsa dualidade razão-sentimento. O raciocínio moral é sempre implicado ou situado. Sempre envolve um balanço entre razão e emoções morais, ainda que certas escolas de pensamento ético insistam numa proposta de arregimentação exclusiva da razão. 
E, por fim, busca-se elementos teóricos e argumentos através dos quais justifica-se a decisão ética formulada, em articulação com a realidade concreta do sistema-mundo, com certo grau de conceptualização abstrata e de experimentação ativa, o que permitirá verificar se o conjunto de avaliações ou julgamentos éticos alcançados são pertinentes na resolução da situação de conflito.

\section{Desenvolvimento}

Situação-limite

Em 1976, no discurso de abertura de um congresso mundial de hemofilia, o hematologista Ilsley Ingram afirmou:

A história da hemofilia mostra a mente humana tentando definir e abranger um misterioso e fascinante fenômeno; e, também, o coração humano, respondendo ao desafio de repetidas adversidades ${ }^{40}$.

Estas adversidades são as situações-limite. Trata-se de um conceito polissêmico, mas alguns autores dão pistas de como é possível articulá-lo com a questão da equidade no acesso aos tratamentos para hemofilia. No senso comum, é aquela situação em que se vivencia experiências diferentes daquelas decorrentes de situações ordinárias ou corriqueiras. Para Berlinguer ${ }^{41}$, os avanços biotecnocientíficos trazem questões morais que se situam na fronteira, isto é, as inovações tecnológicas no campo biomédico (situações emergentes) desafiam certas concepções e normas vigentes, conformando situações-limite. Para Freire ${ }^{42}$, tais situações se referem às condições históricas que impedem as pessoas de terem liberdade e no qual há grandes assimetrias socioeconômicas. Jaspers afirma que o termo situação-limite tem uma conotação existencial (morte, sofrimento, luta, culpa) decorrente de certas circunstâncias da vida 43 . Leopoldo e Silva, assumindo que "no plano da decisão ética, os fatores objetivo e subjetivo não podem ser completamente separados" ${ }^{44}$, pondera:

"A situação-limite configura-se sempre pela insuficiência do valor, mas, repita-se, essa insuficiência não é intrínseca ao próprio valor em si mesmo; ela aparece quando a singularidade dramática da situação em que o sujeito está envolvido o leva a questionar o valor, e a ver que aquilo que o valor representa em termos de bem não coincide com a melhor escolha."

Leopoldo e Silva salienta que "no plano da decisão ética, os fatores objetivo e subjetivo não podem ser completamente separados, e que não podemos eleger apenas um deles como fundamento das opções" ${ }^{44}$, mas é preciso alcançar uma terceira via, ponderando "momentos em que muitas vidas valem o sacrifício de algumas; há momentos em que o sacrifício de uma vida não se justifica pela salvação de muitas" ${ }^{\prime 4}$. Parte da tensão ética que atravessa o problema que elencamos se relaciona ao exposto: como a situação singular e limite que vive uma pessoa com hemofilia, ao tentar acessar o tratamento, se converte num conflito de justiça distributiva, que coloca em oposição vidas identificadas e vidas estatísticas ${ }^{45}$.

As perspectivas acima podem compor um panorama de análise da seguinte maneira: as PCH podem gozar de novos tratamentos que tenham impacto positivo em sua qualidade de vida; mas há condicionantes e determinantes clínicos, éticos, sanitários, sociais e econômicos que compõem a complexa equação de acesso 
ao novo medicamento ${ }^{46}$. Os ciclos de inovação, decorrentes do avanço biotecnocientífico, impõem um ritmo acelerado às interações entre profissionais de saúde, pacientes e indústria de medicamentos, gerando expectativas de efeitos positivos dos novos medicamentos, demandas por atualização de protocolos e pressão nos sistemas de saúde, que precisam readequar orçamentos e processos de aquisição e dispensação. Neste contexto, o gestor tende a pensar em escassez de recursos e em métricas utilitaristas (ex. custo-efetividade ${ }^{47}$ ). E o paciente requer o acesso ao medicamento não apenas para evitar agravos ou sequelas, mas para ter qualidade de vida.

Deve-se destacar os motivos que trazem a questão da qualidade de vida para esta discussão. A hemofilia é uma condição genético-hereditária que afeta, primariamente, o sexo masculino. Por ser uma "doença do sangue", com todos os símbolos implicados neste fato, coloca as famílias nas quais ocorre em dinâmicas de cuidados peculiares, que se impõem pelo "medo de sangrar", com novos limites para meninos que, em nossa sociedade, são cobrados a representar papéis masculinos "fortes" e/ou "temerários" ${ }^{48,49}$. Há um limite silenciado: meninos com hemofilia "não devem" praticar esportes e devem se cuidar para evitar acidentes durante o livre-brincar ${ }^{3}$. Contudo, esse é um limite contornável pelos modelos atuais de tratamento profilático, mas estes são caros.

Há extensa literatura publicada acerca da hemofilia, com livros ${ }^{50}$ e manuais ${ }^{51}$, e não é o foco desta reflexão a descrição pormenorizada dos eventos biológicos ou abordagens biomédicas sobre o assunto. Mas por meio do sentipensar, este texto foi construído e discute uma dimensão da injustiça, que é, primeiramente, vivida e sentida. Em outros termos, pretende-se discutir uma faceta concreta do conflito entre concepções de justiça, que pode ser expressa na seguinte pergunta: buscamos somente dar compensações a quem está em situação de desvantagem ou buscamos dar as mesmas escolhas ou chances às pessoas, independentemente do seu status no sistema-mundo?

Atualmente existem duas modalidades de tratamento de reposição de FC, a primeira forma é baseada em demanda e a segunda forma é profilática ${ }^{50,51}$. O tratamento sob demanda é feito depois de um episódio de sangramento. Já o tratamento profilático é aplicado antes do desenvolvimento de um episódio de hemorragia. Parece óbvio, utilizando-se o princípio de precaução, que adotar um esquema profilático efetivo seria a escolha ética a ser feita. A profilaxia primária é um consenso entre pesquisadores e organizações do campo dos estudos da hemofilia. Um estudo entre Brasil e Canadá, por exemplo, apresenta como principal achado que o aumento do acesso a concentrados de FC para meninos com hemofilia grave é um imperativo global ${ }^{52}$.

No Brasil, foram estabelecidos Protocolos Clínicos e Diretrizes Terapêuticas (PCDT) para o tratamento de hemofilia ${ }^{53}$. Os PCDT que são orientações estruturadas contendo as melhores evidências disponíveis (eficácia, segurança, efetividade e custo-efetividade) para o adequado diagnóstico, tratamento preconizado, medicamentos disponíveis no Sistema Único de Saúde, entre outras orientações a serem seguidas pelos gestores e profissionais de saúde. O protocolo permite que se aporte padrões e orientações técnicas aos cuidados, mas, deve-se reconhecer que, seu caráter é limitado (ao sumário de evidências) e temporalmente circunscrito. 
Manco-Johnson e colaboradores ${ }^{54}$, em 2007, conduziram um ensaio clínico no qual foi demonstrado o efeito protetor da profilaxia, principalmente sobre as lesões articulares, que são um problema recorrente para quem vive com hemofilia. Mas isto implica em custos mais altos que o esquema terapêutico de demanda, o que complica todo o processo de acesso à tecnologia. No mesmo artigo, os autores destacam a segurança que a transição de tecnologias (do uso de FC hemoderivado para o uso de fator recombinante) trouxe para os pacientes, que foram assombrados pelo HIV e pela hepatite, da mesma forma que hoje, o seria por vírus como COVID-19, Dengue, Zika ou Chikungunya.

De 2007 até hoje, houve a disseminação do uso de FC recombinante para tratamento de hemofilia. No Brasil, sua adoção depende de acordos entre o Estado e empresas do setor. E, o Ministério da Saúde do Brasil, apesar de inúmeras dificuldades, sinaliza esta possibilidade, mediante atualização (em elaboração após consulta à comunidade ${ }^{55}$ ) do protocolos clínico e diretriz terapêutica para profilaxia de hemofilia grave ( $^{53}$. No entanto, a comunidade de PCH já sinaliza a demanda por FC recombinantes de longa duração e com individualização de tratamento.

A coexistência de quatro gerações diferentes de abordagens terapêuticas para hemofilia pode gerar um quadro de confusão acerca de escolhas, pois se estabelece a necessidade de compará-las: a primeira geração (década de 1970) corresponde aos FC derivados de plasma; a segunda geração (década de 1990) corresponde aos FC recombinantes; a terceira geração (década de 2010) corresponde aos FC recombinantes de longa duração; e, atualmente, estão em curso pesquisas com terapias gênicas e abordagens moleculares mais complexas. Entre elas variam custos, segurança, eficácia e desfechos ${ }^{56}$.

A análise desse cenário complexo deve ser feita com parcimônia, já que leva ao conflito entre escolhas (melhor opção de tratamento) e valores (deveres ou consequências). Isto é, se a opção é pelo melhor tratamento ou se pela melhor estimativa de custo-efetividade, por exemplo. Este tipo de análise parece saído do mito da cama de Procusto ou da alegoria da cama de Sodoma (Tratado Sanhedrin 109b) e pode ser traduzido da seguinte forma: é o paciente que deve se adequar ao protocolo ou o protocolo que deve ser adequado ao paciente? Mas essa análise não pode ser feita exclusivamente no interior de um modelo de economia da saúde, sem levar em consideração a diversidade de outros critérios, inclusive de direitos humanos. A literatura já tem apontado caminhos, como as análises de decisão baseadas em multicritérios ${ }^{57}$.

No processo de tradução de conhecimento, isto é, da bancada para o leito, pesquisadores clínicos e gestores precisam alcançar consensos acerca de como se aplicar os novos conhecimentos e sobre como devem incorporar as novas tecnologias nos sistemas de saúde. A equação para tratamento da hemofilia (ainda que o desejado sempre fora tratar as pessoas...) é expressa em termos de custos diretos e indiretos de tratamento, do ônus de se viver com hemofilia (burden of disease), do tipo de tecnologia (FC hemoderivado ou recombinante) e da forma de acesso (demanda ou profilaxia em seus diferentes graus) ${ }^{52,58-61}$.

Com estas informações em mãos, frequentemente produzidas por estratégias de sumarização de evidências, hematologistas organizam painéis a fim de estabelecer metas para o tratamento de quem vive com hemofilia. E, de modo geral, o gestor do sistema de saúde é compelido a converter estas metas em protocolos, 
a partir de uma perspectiva utilitarista, que conduz a otimização de recursos e a padronização de tratamentos. Tal padronização atribui UI per capta de FC para o tratamento e estima custos per capta de tratamento. Logicamente, tais cálculos precisam ser feitos a fim de permitir o planejamento de compras ou licitações, que por sua vez, precisam ser previstos em orçamento. Espera-se que um bom gestor preze pela economicidade e contenha custos. E não são poucas as denúncias de sobreprecificação por parte da indústria farmacêutica ${ }^{62}$. Mas superadas as rodadas de precificação de medicamentos, e com a definição de um custo médio por paciente e de previsão de compras, surge outra questão: as doses previstas em protocolo são sugestões ou são limites?

Cabe constatar que as revisões sistemáticas e metanálises, reconhecidas como evidências robustas, trabalham com estimativas (odds ratio, risco relativo, medidas de homogeneidade/heterogeneidade etc.). São abordagens tecnocráticas necessárias, mas baseadas em condições controladas ${ }^{63}$, e que orientam a formulação de protocolos. Contudo, as revisões que embasam os protocolos têm sempre uma limitação temporal. E o mundo acadêmico não é estacionário. Logo, é sempre preciso revisar as revisões.

Outro ponto importante se refere aos desfechos e a magnitude dos efeitos de tratamentos descritos nos protocolos. Novamente, é preciso constatar que os ensaios clínicos randomizados afastam o clínico das evidências anedóticas, isto é, das impressões cotidianas acerca de tratamentos ou condutas, que podem estar debaixo de vieses. No entanto, apesar do risco dos vieses, não se pode desconsiderar que a expressão de uma condição genética ou de uma doença tem aspectos singulares, biológicos ou psicossociais. Segundo Greenhalgh 63, o professor Sackett e colegas ${ }^{64}$ - um dos pais da medicina baseada em evidências (MBE) - "defendem que, antes de colocar um paciente sob tratamento com um medicamento, o médico deve:

Identificar o objetivo final do tratamento para este paciente (cura, prevenção de recidiva, limitação da incapacidade funcional, prevenção de complicações tardias, tranquilidade, efeito paliativo, alívio sintomático etc.).

Selecionar o tratamento mais apropriado utilizando todas as evidências disponíveis (isso inclui avaliar se o paciente necessita mesmo tomar algum medicamento).

Especificar o alvo do tratamento (como você saberá quando interromper o tratamento, modificar sua intensidade ou trocar para outro tratamento?)."

Em outro trecho, a Greenhalgh reflete:

"Assim, enquanto os protagonistas originais da MBE são às vezes equivocadamente apresentados como tendo riscado o pobre paciente do script, na verdade eram muito cuidadosos em apresentar a MBE como determinada pela escolha do paciente (e, consequentemente, como dependente no raciocínio clínico). O "melhor" tratamento não necessariamente é o que demonstrou ser mais eficaz em ensaios clínicos randomizados, mas sim o que melhor se adapta a determinado conjunto de circunstâncias individuais e se alinha com as preferências e as prioridades do paciente."

Estes trechos permitem duas considerações: a de que o tratamento deve ser sempre singular e que, consequentemente, as doses previstas em protocolo são sugestões e não limites. O clínico deve manejar as melhores evidências da literatura e ponderá-las à luz das evidências que o paciente traz (e que ele verifica) e das preferências que expressa o paciente. Do ponto de vista ético, estas são expressões de justiça, de precaução e de consideração dos interesses do paciente. O ato terapêutico não se limita a tecnocracia da dose esta- 
belecida no protocolo, mas depende da formulação adequada de uma conduta baseada sim nas melhores evidências disponíveis, que apontam qual é a posologia que atenderá a singularidade do caso.

\section{Acesso singular}

A decisão do tratamento, pressupõe uma vinculação ética com o paciente, que aceita tratar-se num gesto de confiança e de necessidade. Neste sentido, a decisão clínica conserva uma dimensão de equidade, no qual o médico pondera se está dando a todos os pacientes aquilo que eles necessitam para reestabelecer sua saúde. Uma ação clínica aduzida objetivamente do protocolo operará com outro vetor moral, o de igualdade, isto é, que todos receberão o mesmo tratamento. E o mesmo tratamento, neste caso, significa a negativa da singularidade biopsicossocial dos pacientes, sem dar nenhum efeito às suas necessidades ou exigências. Agir dentro de um parâmetro igualitário de justiça, neste tipo de situação, pode paradoxalmente criar uma iniquidade ou aumentar a injustiça. O paciente que necessite de uma dose maior de medicamento, por estar fora dos parâmetros estabelecidos no protocolo, pode se ver desassistido ou insuficientemente assistido.

A fim de verificar se os argumentos apresentados acima aderem à realidade das situações-limite para as pessoas com hemofilia, fomos buscar argumentos apresentados em decisões judiciais de tratamentos dispensados para hemofilia. Esta análise possibilitou reflexões sobre o acesso singular em situação-limite com foco nos conflitos reais que são levados aos tribunais brasileiros. No total foram encontradas 14 decisões judiciais (nomeadas DJ-1 a DJ-14) na capital do país e Estado-foco da pesquisa e seus dados foram dispostos em uma tabela (Material Suplementar) com a categorização de argumentos disponíveis nestes documentos (do Governo, médico e magistrados). Deste total, 13 foram favoráveis e 1 não favorável ao acesso medicamentoso, sendo que a última era relacionada a pessoa em vivência com a hemofilia B grave. O modelo de Badim (2011) ${ }^{65}$ com adaptações foi o parâmetro para organização de dados. Analisamos os argumentos dos representantes do Estado, dos profissionais de saúde convidados a se manifestar e do juiz ou magistrado.

O discurso jurídico em saúde presente nesta amostra se pauta nos princípios e diretrizes do SUS: universalidade, igualdade, integralidade, gratuidade, participação da comunidade, descentralização, regionalização e hierarquização de ações e serviços de saúde ${ }^{66}$, e ainda traz certos elementos de influência Rawlsiana ${ }^{67}$, o mesmo que afirma ser óbvio uma sociedade concreta raramente ser bem-ordenada, já que "o que é justo e o que é injusto está geralmente sob disputa"(p.5) ${ }^{68}$. Fazem parte desta disputa algumas pessoas com vidas reais, comuns, em situações extraordinárias: a vivência com uma doença rara, não perceptível ao primeiro olhar, porém sentida por este paciente alargado ${ }^{69}$ como a "criança de tenra idade e que necessita do tratamento para ter uma vida digna" (DJ01 e DJ07).

A leitura das duas decisões aparentemente aponta para uma demanda profilática de tratamento nestes casos. Mas há em todas um consenso expresso, tanto por parte de especialistas hematologistas, quanto do corpo técnico do Direito: o da gravidade dos eventos de sangramento com possibilidade de lesões e sequelas que comprometam a saúde e à vida. Os argumentos biológicos e de direitos humanos se repetem nos discursos especialistas (médico e jurídico) a tal ponto que há um padrão de argumentação que prevê a homogeneidade, a similaridade, porém escapa a singularidade, prevalecendo o limite em detrimento a sugestão. Num olhar 
geral: o foco do Estado está no custo e na disponibilidade do tratamento; o foco dos profissionais de saúde está nos desfechos clínicos; e, por fim, o foco do tribunal está na questão dos direitos garantidos pelo Estado. Os três discursos são legítimos, mas conflitantes. E se embasam em concepções éticas distintas, que oscilam entre o utilitarismo e o deontologismo. Sabe-se que hoje, o sistema de decisões jurídicas em saúde conta com a assistência de um aparato tecnocrático (NATJUS e e-NatJus) que, em última instância não deve acomodar uma visão limitada ou caricatural da medicina baseada em evidências, que implique em risco de acentuação de certas características dos arcabouços ético-normativos que orientam os posicionamentos das partes envolvidas no conflito. Deve-se recordar que a elaboração de pareceres por partes de profissionais de saúde servirá de prova pericial nas demandas. Isso significa que os profissionais que emitem pareceres precisam ter uma visão adequada e crítica acerca do uso de evidências. Essa é uma discussão incipiente, mas necessária ${ }^{70}$.

No caso da hemofilia, o tratamento tem por meta um desfecho duro: evitar o sangramento. É preciso considerar que a condição afeta majoritariamente meninos, que no Brasil, por questões culturais (e meninas também possam fazer as mesmas coisas se assim desejarem), gostam de correr ao ar livre, de subir em árvores, de jogar futebol e de esportes de contato. Mas os meninos com hemofilia vivem contidos ou limitados, indiretamente, pelo custo per capta do FC, isto é, pelo limite da prescrição das doses de resgate que deverão tomar quando tem episódios de sangramento decorrentes da "indisciplinada lide" de querer brincar com liberdade. Não podem fruiu de uma vida plena pois estão em desvantagem causada pela loteria biológica (não escolheram nascer com hemofilia) e pela loteria social (não escolheram não ter acesso a tratamentos efetivos). Mas são compensados por tratamentos que limitam sangramentos e permitem que vivam. E os protocolos atuais estabelecem as formas e dimensões da gestão biopolítica dessas vidas. Numa sociedade justa, as compensações são necessárias, mas talvez não sejam suficientes para dar as PCH as mesmas escolhas ou chances, independentemente do seu status no sistema-mundo.

A profilaxia atualmente dispensada nos protocolos disponíveis no SUS é limítrofe. A possível utilização de hemoderivados não está livre dos riscos. A disponibilidade da segunda geração de FC, que são mais seguros, depende de pactos de transferência tecnológica ou de importação. A terceira geração tem custos elevados, mas fornecem ganhos em termos de qualidade de vida. Nas demandas judiciais, o que se pede, de modo geral, é o acesso a 2a e 3a geração de FC, em função dos efeitos e dos ganhos qualitativos. O acesso singular ao FC, isto é, de acordo com a necessidade individual e com o estilo de vida, garantem igualdade de oportunidade e, ainda, o exercício das capacidades descritas por Nussbaum, como a saúde corporal ou as interações lúdicas ${ }^{71}$.

Hoje, há 13 mil brasileiros acometidos pela hemofilia e que podem ter vidas com relativa qualidade, desde que recebam tratamentos pensados à partir de protocolos terapêuticos singulares, nos quais os regimes de profilaxia são implementados com a realização de estudos farmacocinéticos individuais, nos quais se avalia a reação do organismo às doses de fator anticoagulante, com novos estudos tem apontado ${ }^{72}$. Talvez seja necessário rememora-se a perspectiva do cuidado centrado no paciente e o rol de ações de humanização estabelecidas no interior do SUS, para garantir a singularidade do cuidado. Mas entendemos, obviamente, que não se pode ofertar um tratamento singular em detrimento do tratamento de outros grupos de pessoas. Da mesma forma que não se pode privar um indivíduo ou abandoná-lo sem que tenha recebido os devidos cuidados. Mas 
salientamos que esse é um falso dilema ou um conflito que pode ser reconfigurado em outros termos, uma vez que se pressupõe que, no interior do SUS, todo cuidado é integral e o acesso é universal. Recursos financeiros são finitos. Mas a capacidade de gerenciar o sistema de saúde pode ser sempre otimizada a fim de garantir o adequado tratamento às pessoas. Novamente, reconhecemos que essa não é uma discussão simples e que não pode ser feita de maneira leviana. Mas nosso intuito é chamar a atenção para o fato de que, invariavelmente, se estabelece uma polarização entre fornecer cuidados para uma pessoa com doença rara ou deficiência e a disposição do Estado a pagar por isso, que é ocultada em argumentos (rasos) do tipo: "se eu der o medicamento $x$ de alto custo para o fulano, mil crianças ficarão sem vacinas".

Compreendemos que, para evitar o conflito de perspectivas, é necessário olhar a questão do financiamento dos tratamentos para doenças raras com atenção, lançando mão, por exemplo, de aprofundamentos teóricos norteados pelo rol de artigos da Declaração Universal sobre Bioética e Direitos Humanos (DUBDH) ou por aproximações baseadas em equidade ${ }^{73}$. Nas decisões judiciais colhidas, a argumentação utilitarista (com suas considerações sobre vantagens, desvantagens, riscos, custos e desfechos) tem sido contraposta com um modelo que aponta soluções pragmáticas baseadas no impacto dos novos medicamentos na qualidade de vida das pessoas com hemofilia, com características mais rawlsianas. Num país que possui um sistema universal de saúde, como o Brasil, mas que apresenta desigualdades persistentes, a presente discussão é necessária e urgente.

Considerações finais

A discussão da equidade na situações-limite do acesso singular a tratamento medicamentoso preventivo para $\mathrm{PCH}$ tem se tornado uma constante nos tribunais. E essa é um tema compartilhado com diversas doenças raras, que são alvo de inovações farmacêuticas pautadas numa lógica de medicina personalizada e de custos elevados. A fim de (não) concluir, retomamos as três condições propostas na metodologia e apresentamos nossas considerações finais:

(a) A condição verídica: apresentamos elementos da questão bioética do valor de uma vida versus o valor do tratamento de uma condição genética rara que, em concepções utilitaristas que permeiam o cenário da economia da saúde pública, se põe como o valor do tratamento de um versus o valor de tratamento de muitos. Há possibilidade de outros enquadramentos éticos para o assunto, mas há uma repercussão prática e imediata, negociada na por atores morais nos tribunais, que tem efeitos visíveis nas condições de acesso a tratamento limítrofe ou a tratamento que garanta qualidade de vida.

(b) A condição realista: os recursos financeiros disponíveis para a oferta de tratamentos dentro de um sistema de saúde são finitos. Todavia, este mesmo sistema, se universal e equitativo, deve garantir igualdade de oportunidade no acesso. A garantia do "maior bem para o maior número de pessoas" dentro do sistema, não deveria significar a oferta do tratamento mínimo, mas sim a oferta do tratamento necessário. Pode-se retomar a reflexão de que este sistema não deveria 
somente dar compensações a quem está em situação de desvantagem, mas deveria garantir as mesmas chances às pessoas, independentemente do seu status.

(c) A condição pragmática: o acesso ao medicamento (de alto custo) é uma situação-limite que implica em reflexão do valor das vidas estatísticas versus o valor das vidas identificadas. Assim, é necessário sentipensar as possíveis respostas ou proposições a serem apresentadas com base na experiência concreta, isto é, dos desdobramentos regulatórios e judiciais no processo de acesso ao tratamento de hemofilia, enxergando este sujeito como uma pessoa que deva ter acesso ao adequado tratamento, aquele que garanta qualidade de vida, e que não apenas vida limítrofe. E, a contraposição do acesso de um versus o aceso de muitos, não deve ser um conflito moral circunscrito ao médico ou ao paciente, mas deve ser um exercício reflexivo permanente do gestor que deve prover os mecanismos para que esse conflito seja sentido com menos força no espaço moral mais sensível: o do cuidado. Num país heterogêneo como Brasil, compreender os itinerários terapêuticos e os custos implicados na falta de acesso, isto é, saber quanto custa para o sistema deixar um paciente sem o tratamento adequado, pode ser um dos mecanismos para atender as demandas específicas dos grupos de pacientes e a minorar conflitos de alocação de recursos.

\section{BIBLIOGRAFIA}

1. Blanchette VS, Srivastava A. Definitions in hemophilia: resolved and unresolved issues. Semin Thromb Hemost [Internet]. 2015;41(8):819-25. Available from: https://www.ncbi.nlm.nih.gov/pubmed/26479892

2. Timmer MA, Pisters MF, de Kleijn P, de Bie RA, Fischer K, Schutgens RE. Differentiating between signs of intra-articular joint bleeding and chronic arthropathy in haemophilia: a narrative review of the literature. Haemophilia [Internet]. 2015;21(3):289-96. Available from: https://www.ncbi.nlm.nih.gov/pubmed/25854291

3. Marques TF. Princípio da autonomia e a atividade física: influência dos profissionais de saúde nas práticas físicas de pessoas com hemofilia [Internet]. Universidade de Brasília; 2018. Available from: https://repositorio.unb.br/handle/10482/35137

4. Blanchette VS, Key NS, Ljung LR, Manco-Johnson MJ, van den Berg HM, Srivastava A. Definitions in hemophilia: communication from the SSC of the ISTH. J Thromb Haemost [Internet]. 2014 Nov;12(11):1935-9. Available from: https://www.ncbi.nlm.nih.gov/pubmed/25059285

5. Aureliano W de A. Trajetórias Terapêuticas Familiares: doenças raras hereditárias como sofrimento de longa duração. Cien Saude Colet [Internet]. 2018 Feb;23(2):369-80. Available from: http://www.scielo.br/scielo.php?script=sci_arttext\&pid=S1413-81232018000200369\&lng=pt\&tlng=pt

6. Sulser E. A patient's perspective on hemophilia. Semin Hematol [Internet]. 2006;43(2 Suppl 3):S13-6. Available from: https://www.ncbi.nlm.nih.gov/pubmed/16631822

7. Schramm W. The history of haemophilia - a short review. Thromb Res [Internet]. 2014;134 Suppl:S4-9. Available from: https://www.ncbi.nIm.nih.gov/pubmed/24513149

8. Orsini M. Reframing Medical Injury? Viewing People With Hemophilia as Victims of Cultural Injustice. Soc Leg Stud [Internet]. 2007 Jun 1;16(2):241-58. Available from: https://doi.org/10.1177/0964663907076533

9. Wiedebusch S, Pollmann H, Siegmund B, Muthny FA. Quality of life, psychosocial strains and coping in 
parents of children with haemophilia. Haemophilia [Internet]. 2008;14(5):1014-22. Available from: https://www.ncbi.nlm.nih.gov/pubmed/18624702

10. Makris M, Hermans C. A golden age for Haemophilia treatment? Haemophilia [Internet]. 2018;24(2):175-6. Available from: https://www.ncbi.nlm.nih.gov/pubmed/29601683

11. Batty P, Lillicrap D. Advances and Challenges for Hemophilia Gene Therapy. Hum Mol Genet [Internet]. 2019; Available from: https://www.ncbi.nlm.nih.gov/pubmed/31332444

12. Czeresnia D, Maciel EMG de S, Oviedo RAM. Os sentidos da saúde e da doença [Internet]. Os sentidos da saúde e da doença. Editora FIOCRUZ; 2013. Available from: http://books.scielo.org/id/8s5m4

13. Helman CG. Cultura, saúde e doença. 5th ed. Porto Alegra: Artmed; 2009. 432 p.

14. Huyard C. How did uncommon disorders become "rare diseases"? History of a boundary object. Sociol Heal IIIn [Internet]. 2009/04/29. 2009;31(4):463-77. Available from: http://www.ncbi.nlm.nih.gov/pubmed/19397760

15. Huyard C. What, if anything, is specific about having a rare disorder? Patients\&\#039; judgements on being ill and being rare. Heal Expect [Internet]. 2009;12(4):361-70. Available from: http://dx.doi.org/10.1111/j.1369-7625.2009.00552.x

16. Rosendaal FR, Smit C, Briet E. Hemophilia treatment in historical perspective: a review of medical and social developments. Ann Hematol [Internet]. 1991;62(1):5-15. Available from: https://www.ncbi.nlm.nih.gov/pubmed/1903310

17. Ar MC, Baslar Z, Soysal T. Personalized prophylaxis in people with hemophilia A: challenges and achievements. Expert Rev Hematol [Internet]. 2016;9(12):1203-8. Available from: https://www.ncbi.nlm.nih.gov/pubmed/27809624

18. Ives J, Dunn M, Cribb A. Empirical bioethics: theoretical and practical perspectives. 1st ed. Ives J, Dunn M, Cribb A, editors. Vol. 37. Cambridge: Cambridge University Press; 2017. 282p p.

19. Davies R, Ives J, Dunn M. A systematic review of empirical bioethics methodologies. BMC Med Ethics [Internet]. 2015;16:15. Available from: https://www.ncbi.nlm.nih.gov/pubmed/25885575

20. Zeiler K, De Boer M. The Empirical and the Philosophical in Empirical Bioethics: Time for a Conceptual Turn. AJOB Empir Bioeth [Internet]. 2020 Jan 2;11(1):11-3. Available from: https://www.ncbi.nlm.nih.gov/pubmed/32096732

21. Huxtable R, Ives J. Mapping, framing, shaping: a framework for empirical bioethics research projects. BMC Med Ethics [Internet]. 2019;20(1):86. Available from: https://www.ncbi.nlm.nih.gov/pubmed/31775725

22. Dunn M, Ives J. Methodology, Epistemology, and Empirical Bioethics Research: A Constructive/ist Commentary. Am J Bioeth [Internet]. 2009 Jun 22;9(6-7):93-5. Available from: https://www.ncbi.nlm.nih.gov/pubmed/19998135

23. Ives J. A method of reflexive balancing in a pragmatic, interdisciplinary and reflexive bioethics. Bioethics [Internet]. 2014;28(6):302-12. Available from: https://www.ncbi.nlm.nih.gov/pubmed/23444909

24. Ives J, Draper H. Appropriate methodologies for empirical bioethics: it's all relative. Bioethics [Internet]. 2009;23(4):249-58. Available from: https://www.ncbi.nlm.nih.gov/pubmed/19338525

25. Ives J. "Encounters with experience": empirical bioethics and the future. Heal Care Anal [Internet]. 2008;16(1):1-6. Available from: https://www.ncbi.nlm.nih.gov/pubmed/18080836

26. Spielthenner G. The casuistic method of practical ethics. Theor Med Bioeth [Internet]. 2016 Oct 17;37(5):417-31. Available from: http://link.springer.com/10.1007/s11017-016-9382-8

27. Garrafa V. Reflexões bioéticas sobre ciência, saúde e cidadania. Rev Bioética. 2009;7(1).

28. Garrafa V. Multi-inter-transdisciplinaridade, complexidade e totalidade concreta em bioética. In: 
Garrafa V, Kottow M, Saada A, editors. Bases conceituais da bioética: enfoque latino-amer [Internet]. 1st ed. São Paulo: Ed. Gaia - Redbioética Unesco; 2006. p. 67-86. Available from: https://unesdoc.unesco.org/ark:/48223/pf0000150148

29. Manchola-Castillo C, Garrafa V. De la fundamentación a la intervención: una propuesta metodológica (inarrativa!) para la Bioética de Intervención. Rev Bras Bioética [Internet]. 2019 Aug 16;15(1):1-18. Available from: http://periodicos.unb.br/index.php/rbb/article/view/26669

30. Manchola Castillo $\mathrm{CH}$, Solbakk JH. Bioethics and imagination: towards a narrative bioethics committed to social action and justice. Med Humanit [Internet]. 2017 Sep;43(3):166-71. Available from: http://mh.bmj.com/lookup/doi/10.1136/medhum-2016-011079

31. Manchola C. Tres apuestas por una bioética práctica. Rev Bioética [Internet]. 2017 Aug;25(2):264-74. Available from: http://www.scielo.br/scielo.php?script=sci_arttext\&pid=S1983$80422017000200264 \& n r m=$ iso

32. SES-DF. PORTARIA N ${ }^{\circ}$ 725, DE 05 DE JULHO DE 2018 [Internet]. Brasília-DF; 2018. Available from: http://www.sinj.df.gov.br/sinj/Norma/a60a79c3c69941239367e432b8f528f0/Portaria_725_05_07_201 8.html

33. Borda OF, Moncayo VM. Una sociología sentipensante para América Latina. 1st ed. CLACSO, editor. Bogotá: Siglo del hombre; 2009. 492 p.

34. Galeano E. O livro dos abraços. 9th ed. Porto Alegre: L\&PM; 2002. 270p p.

35. Santos B de S. Epistemologías del sur. Utopía y Prax Latinoam [Internet]. 2011;16(54):17-39. Available from: http://hdl.handle.net/10316/42229

36. Moraes MC, Torre S de la. Sentipensar sob o olhar autopoiético: estratégias para reencantar a educação. 1st ed. Petrópolis/Rio de Janeiro: Vozes; 2004. 176p p.

37. Damásio A. What role do emotions play in consciousness? [Internet]. YouTube. 2010 [cited 2020 Feb 25]. Available from: https://www.youtube.com/watch?v=Aw2yaozi0Gg

38. Maturana HR, Varela FJ. A árvore do conhecimento - As bases biológicas da compreensão humana. 1st ed. São Paulo: Palas Athena; 2001. 283p p.

39. Feitosa SF. O processo de territorialização epistemológica da bioética de intervenção: por uma prática bioética libertadora. Universidade de Brasília; 2015.

40. Ingram GIC. The history of haemophilia*, $\dagger$. Haemophilia [Internet]. 1997 Jun;3(S1):5-15. Available from: http://doi.wiley.com/10.1111/j.1365-2516.1997.tb00168.x

41. Garrafa V. Bioética cotidiana. Vol. 21, Cadernos de Saúde Pública . scielo ; 2005. p. 333-4.

42. Freire P. Pedagogia do Oprimido. 17th ed. Rio de Janeiro: Editora Paz e Terra; 1987. 107 p.

43. Thornhill C, Miron R. Karl Jaspers. In: Zalta EN, editor. The Stanford Encyclopedia of Philosophy. Spring 202. Metaphysics Research Lab, Stanford University; 2020.

44. Franklin Leopoldo e Silva. Ética e situações-limite. Revista CULT [Internet]. 2010 Apr;48-51. Available from: https://revistacult.uol.com.br/home/etica-e-situacoes-limite/

45. Cohen IG, Daniels N, Eyal NM. Identified versus statistical lives : an interdisciplinary perspective. Population-level bioethics series. Oxford ; New York: Oxford University Press; 2015. xii, 227 pages.

46. Petrini P. Identifying and overcoming barriers to prophylaxis in the management of haemophilia. Haemophilia [Internet]. 2007;13 Suppl 2:16-22. Available from: https://www.ncbi.nlm.nih.gov/pubmed/17685919

47. Miners $\mathrm{AH}$, Lee $\mathrm{CA}$. Setting research priorities to improve cost-effectiveness estimations of primary prophylaxis with clotting factor for people with severe haemophilia. Haemophilia [Internet]. 2004;10 Suppl 1:58-62. Available from: https://www.ncbi.nlm.nih.gov/pubmed/14987250 
48. Kalmar L, Oliffe JL, Currie LM, Jackson S, Gue D. Men, Masculinities, and Hemophilia. Am J Mens Heal [Internet]. 2016;10(6):NP22-32. Available from: https://www.ncbi.nlm.nih.gov/pubmed/26229052

49. Reinicke K, Sogaard IS, Mentzler S. Masculinity Challenges for Men With Severe Hemophilia. Am J Mens Heal [Internet]. 2019;13(4):1557988319872626. Available from:

https://www.ncbi.nlm.nih.gov/pubmed/31451017

50. Lee CA, Berntorp EE, Hoots WK. Textbook of hemophilia. 3th ed. Sussex: John Wiley \& Sons; 2014. 560 p.

51. DAET-MS. Manual de Hemofilia. 2ª . Brasília-DF: Ministério da Saúde; 2015. 80p p.

52. Carneiro JDA, Blanchette V, Ozelo MC, Antunes S V., Villaca PR, Young NL, et al. Comparing the burden of illness of haemophilia between resource-constrained and unconstrained countries: the São PauloToronto Hemophilia Study. Haemophilia [Internet]. 2017 Sep;23(5):682-8. Available from: http://doi.wiley.com/10.1111/hae.13230

53. SAS-MS. Protocolo de Uso de Profilaxia Primária para Hemofilia Grave. [Internet]. PORTARIA N ${ }^{\circ} 364$, DE $^{2}$ 6 DE MAIO DE 2014. 2014. Available from:

http://bvsms.saude.gov.br/bvs/saudelegis/sas/2014/prt0364_06_05_2014.html

54. Manco-Johnson MJ, Abshire TC, Shapiro AD, Riske B, Hacker MR, Kilcoyne R, et al. Prophylaxis versus episodic treatment to prevent joint disease in boys with severe hemophilia. N Engl J Med [Internet]. 2007;357(6):535-44. Available from: https://www.ncbi.nlm.nih.gov/pubmed/17687129

55. CONITEC/MS. Relatório de Recomendação - Protocolo de Uso Profilaxia Primária para Hemofilia grave [Internet]. Brasília-DF; 2019. Available from:

http://conitec.gov.br/images/Consultas/Relatorios/2019/Relatorio_PCDT_ProfilaxiaPrimariaGrave_CP7 8_2019.pdf

56. Thorat T, Neumann PJ, Chambers JD. Hemophilia Burden of Disease: A Systematic Review of the CostUtility Literature for Hemophilia. J Manag care Spec Pharm. 2018 Jul;24(7):632-42.

57. Castro Jaramillo HE, Goetghebeur M, Moreno-Mattar O. TESTING MULTI-CRITERIA DECISION ANALYSIS FOR MORE TRANSPARENT RESOURCE-ALLOCATION DECISION MAKING IN COLOMBIA. Int J Technol Assess Health Care [Internet]. 2016/10/03. 2016;32(4):307-14. Available from: https://www.cambridge.org/core/article/testing-multicriteria-decision-analysis-for-more-transparentresourceallocation-decision-making-in-colombia/F845945DC1DB7231AC51B20DF1C65728

58. Chen SL. Economic costs of hemophilia and the impact of prophylactic treatment on patient management. Am J Manag Care [Internet]. 2016;22(5 Suppl):s126-33. Available from: https://www.ncbi.nlm.nih.gov/pubmed/27266809

59. O'Hara J, Hughes D, Camp C, Burke T, Carroll L, Diego DG. The cost of severe haemophilia in Europe: the CHESS study. Orphanet J Rare Dis [Internet]. 2017;12(1):106. Available from: https://www.ncbi.nlm.nih.gov/pubmed/28569181

60. Pokras SM, Petrilla AA, Weatherall J, Lee WC. The economics of inpatient on-demand treatment for haemophilia with high-responding inhibitors: a US retrospective data analysis. Haemophilia [Internet]. 2012;18(2):284-90. Available from: https://www.ncbi.nlm.nih.gov/pubmed/21812862

61. Siddiqi A-A, Ebrahim SH, Soucie JM, Parker CS, Atrash HK. Burden of Disease Resulting from Hemophilia in the U.S. Am J Prev Med [Internet]. 2010 Apr;38(4):S482-8. Available from: https://www.ncbi.nlm.nih.gov/pubmed/20331947

62. Angell M. A verdade sobre os laboratórios farmacêuticos: Como somos enganados e o que podemos fazer a respeito. 1st ed. Öven Ustaalioglu BB, editor. Rio de Janeiro: Record; 2007. 319p p.

63. Greenhalgh T. How to read a paper: Papers that summarise other papers (systematic reviews and meta-analyses). BMJ [Internet]. 1997 Sep 13;315(7109):672-5. Available from:

http://www.bmj.com/cgi/doi/10.1136/bmj.315.7109.672 
64. Sackett DL, Haynes RB, Tugwell P. Clinical epidemiology: a basic science for clinical medicine. 1st ed. Öven Ustaalioglu BB, editor. Boston, USA: Little, Brown and Company; 1985. 370p p.

65. Marques SB, Paulo S. O direito ao acesso universal a medicamentos no Brasil : diálogos entre o direito, a política e a técnica $\mathrm{O}$ direito ao acesso universal a medicamentos no Brasil : diálogos entre o direito, a política e a técnica médica . [Internet]. Universidade de São Paulo (USP); 2011. Available from: https://teses.usp.br/teses/disponiveis/6/6135/tde-31102011-100650/publico/SilviaBadim.pdf

66. Paim JS. O que é o SUS. Rio de Janeiro: Editora FIOCRUZ; 2009.

67. Paranhos DG de AM e, Matias EA, Monsores N, Garrafa V. As teorias da justiça, de John Rawls e Norman Daniels, aplicadas à saúde. Saúde em Debate. 2018;42(119):1002-11.

68. Rawls J. Uma teoria da justiça. São Paulo: Martins Fontes; 2000.

69. Barbosa RL, Portugal S. O Associativismo faz bem à saúde? O caso das doenças raras. Cien Saude Colet [Internet]. 2018 Feb;23(2):417-30. Available from:

http://www.scielo.br/scielo.php?script=sci_arttext\&pid=S1413-81232018000200417\&lng=pt\&tlng=pt

70. MARIANO CM, FURTADO ET, ALBUQUERQUE FB, PEREIRA FHLCDAS. Diálogos sanitários interinstitucionais e a experiência de implantação do NAT-JUS . Vol. 5, Revista de Investigações Constitucionais . scielo ; 2018. p. 169-88.

71. Dixon R, Nussbaum MC. Children's Rights and a Capabilities Approach: The Question of Special Priority. Cornell Law Rev. 2012;97(May):549-94.

72. Dargaud Y, Delavenne X, Hart DP, Meunier S, Mismetti P. Individualized PK-based prophylaxis in severe haemophilia. Haemophilia [Internet]. 2018 Mar;24:3-17. Available from:

http://doi.wiley.com/10.1111/hae.13397

73. Wagner M, Khoury H, Willet J, Rindress D, Goetghebeur M. Can the EVIDEM Framework Tackle Issues Raised by Evaluating Treatments for Rare Diseases: Analysis of Issues and Policies, and Context-Specific Adaptation. Pharmacoeconomics [Internet]. 2016 Mar 7;34(3):285-301. Available from: http://www.ncbi.nlm.nih.gov/pmc/articles/PMC4766242/?tool=pubmed 
Material Suplementar: Quadro de análise dos processos judiciais sobre acesso a tratamento de hemofilia disponíveis na base de dados do Tribunal de Justiça do Distrito Federal e dos Territórios (TJDFT) e no Tribunal Regional Federal da 1ạ Região (TRF1) - circunscrição do DF

\begin{tabular}{|c|c|c|c|c|c|c|c|}
\hline № & $\begin{array}{l}N^{\circ} \text { DO PROCES- } \\
\text { SO }\end{array}$ & SENTENÇA & votos & $\begin{array}{l}\text { TIPO DE HE- } \\
\text { MOFILIA }\end{array}$ & $\begin{array}{c}\text { ARGUMENTOS GOVERNO DO } \\
\text { DISTRITO FEDERAL }\end{array}$ & $\begin{array}{l}\text { ARGUMENTOS TÉCNICOS (PRO- } \\
\text { FISSIONAL DE SAÚDE) }\end{array}$ & ARGUMENTOS TÉCNICOS (JUIZ) \\
\hline \multirow{4}{*}{ DJ1 } & \multirow{4}{*}{$\begin{array}{l}20110020069273 \\
\text { MSG }\end{array}$} & \multirow{4}{*}{ Favorável } & \multirow{4}{*}{$\begin{array}{l}\text { Decisão } \\
\text { unânime }\end{array}$} & \multirow{4}{*}{ A, grave } & Alto custo. & $\begin{array}{l}\text { A criança necessita dessa medi- } \\
\text { cação até o completo crescimen- } \\
\text { to e desenvolvimento corporal. }\end{array}$ & $\begin{array}{l}\text { Criança de tenra idade e que neces- } \\
\text { sita do tratamento para ter uma } \\
\text { vida digna. }\end{array}$ \\
\hline & & & & & $\begin{array}{l}\text { Não previsto nos protocolos } \\
\text { clínicos do Distrito Federal. }\end{array}$ & $\begin{array}{l}\text { Observância ao princípio a digni- } \\
\text { dade humana. }\end{array}$ & Dever do Estado \\
\hline & & & & & $\begin{array}{l}\text { Há alternativa disponível } \\
\text { (Concentrado de fator VIII de } \\
\text { origem plasmática). }\end{array}$ & $\begin{array}{l}\text { Medicamento similar oferece } \\
\text { risco de alergias (alergia e anafi- } \\
\text { laxia, necessitando de tratamen- } \\
\text { to hospitalar emergencial). }\end{array}$ & Direito à saúde \\
\hline & & & & & & $\begin{array}{l}\text { Medicamento similar oferece } \\
\text { risco de contaminação por pató- } \\
\text { genos, que podem desencadear } \\
\text { outras enfermidades conhecidas } \\
\text { e não conhecidas, agravadas por } \\
\text { mutações genéticas, sendo des- } \\
\text { conhecido o grau de virulência e } \\
\text { letalidade. }\end{array}$ & \\
\hline \multirow{3}{*}{ DJ2 } & \multirow{3}{*}{$\begin{array}{l}20110020077613 \\
\text { MSG }\end{array}$} & \multirow{3}{*}{ Favorável } & \multirow{3}{*}{$\begin{array}{l}\text { Decisão } \\
\text { unânime }\end{array}$} & \multirow{3}{*}{ A, grave } & Alto custo. & $\begin{array}{l}\text { A medicação descrita pelo médi- } \\
\text { co é a mais adequada para o } \\
\text { caso. }\end{array}$ & $\begin{array}{l}\text { Dever do Estado o direito à vida e à } \\
\text { saúde. }\end{array}$ \\
\hline & & & & & $\begin{array}{l}\text { Não previsto nos protocolos } \\
\text { clínicos do Distrito Federal. }\end{array}$ & & $\begin{array}{l}\text { Melhor recomendação de seguran- } \\
\text { ça à saúde e à vida. }\end{array}$ \\
\hline & & & & & $\begin{array}{l}\text { Inviável a medicação prescri- } \\
\text { ta pelo médico do próprio DF } \\
\text { ser a única solução do pro- } \\
\text { blema. }\end{array}$ & & \\
\hline \multirow{2}{*}{ DJ3 } & \multirow{2}{*}{$\begin{array}{c}20110020052904 \\
\text { MSG }\end{array}$} & \multirow[b]{2}{*}{ Favorável } & \multirow{2}{*}{$\begin{array}{l}\text { Decisão } \\
\text { unânime }\end{array}$} & \multirow[b]{2}{*}{ A, grave } & Alto custo. & $\begin{array}{l}\text { Faz uso desde os } 3 \text { meses de } \\
\text { idade. }\end{array}$ & $\begin{array}{l}\text { Dever do Estado o direito à vida e à } \\
\text { saúde. }\end{array}$ \\
\hline & & & & & $\begin{array}{l}\text { Possui burocrático trâmite } \\
\text { para sua obtenção. }\end{array}$ & $\begin{array}{l}\text { Redução de sangramentos, evitar } \\
\text { lesões crônicas e diminuir risco } \\
\text { de morte. }\end{array}$ & Imperativo de solidariedade social. \\
\hline
\end{tabular}




\begin{tabular}{|c|c|c|c|c|c|c|c|}
\hline & & & & & $\begin{array}{l}\text { medicamento pleiteado não } \\
\text { faz parte do protocolo do SUS }\end{array}$ & & $\begin{array}{l}\text { Respeito indeclinável à vida e a } \\
\text { saúde humana. }\end{array}$ \\
\hline & & & & & & & $\begin{array}{l}\text { Distribuição gratuita de medica- } \\
\text { mentos em favor de pessoas caren- } \\
\text { tes. }\end{array}$ \\
\hline & & & & & & & $\begin{array}{l}\text { É portador de doença grave, neces- } \\
\text { sitando, de forma urgente. }\end{array}$ \\
\hline & & & & & & & $\begin{array}{l}\text { Não observância a reserva do pos- } \\
\text { sível. }\end{array}$ \\
\hline & & & & & & & $\begin{array}{l}\text { Cede o interesse financeiro e se- } \\
\text { cundário do Estado perante a vida } \\
\text { do indivíduo. }\end{array}$ \\
\hline & & & & & & & $\begin{array}{l}\text { Não encerra somente uma promes- } \\
\text { sa de atuação do Estado, mas tem } \\
\text { aplicação imediata. }\end{array}$ \\
\hline \multirow{6}{*}{ DJ4 } & \multirow{6}{*}{$\begin{array}{c}20110020051570 \\
\text { MSG }\end{array}$} & \multirow{6}{*}{ Favorável } & \multirow{6}{*}{$\begin{array}{l}\text { Decisão } \\
\text { unânime }\end{array}$} & \multirow{6}{*}{ A, grave } & $\begin{array}{l}\text { O Distrito Federal pleiteia a } \\
\text { substituição pelo fator VIII } \\
\text { plasmático. }\end{array}$ & $\begin{array}{l}\text { A medicação necessária ao tra- } \\
\text { tamento e essencial para o con- } \\
\text { trole da doença. }\end{array}$ & $\begin{array}{l}\text { Dever do Estado o direito à vida e à } \\
\text { saúde (art. } 196 \text { da CF e } 207 \text { da } \\
\text { LODF). }\end{array}$ \\
\hline & & & & & & & $\begin{array}{l}\text { Poder Público garantir acesso uni- } \\
\text { versal e igualitário. }\end{array}$ \\
\hline & & & & & & $\begin{array}{l}\text { Produto não derivado de san- } \\
\text { gue/plasma humano a fim de } \\
\text { evitar a contaminação do pacien- } \\
\text { te por organismos transmitidos } \\
\text { pelo sangue humano e deriva- } \\
\text { dos, como vírus e príons (partes } \\
\text { de proteínas). }\end{array}$ & $\begin{array}{l}\text { A assistência à saúde sem obstácu- } \\
\text { los no acesso dos mais necessitados } \\
\text { aos tratamentos necessários ao } \\
\text { restabelecimento de suas condi- } \\
\text { ções de saúde. }\end{array}$ \\
\hline & & & & & & & $\begin{array}{l}\text { Compete ao DF prestação de assis- } \\
\text { tência farmacêutica e a garantia de } \\
\text { acesso da população aos medica- } \\
\text { mentos necessários. }\end{array}$ \\
\hline & & & & & & & $\begin{array}{l}\text { O acesso ao medicamento garante } \\
\text { preservação da sua vida. }\end{array}$ \\
\hline & & & & & & & $\begin{array}{l}\text { Manutenção da eficácia e integri- } \\
\text { dade de direitos individuais e/ou } \\
\text { coletivos. }\end{array}$ \\
\hline
\end{tabular}




\begin{tabular}{|c|c|c|c|c|c|c|c|}
\hline \multirow[t]{2}{*}{ DJ5 } & \multirow[t]{2}{*}{$\begin{array}{c}20110020154251 \\
\text { MSG }\end{array}$} & \multirow[t]{2}{*}{ Favorável } & \multirow[t]{2}{*}{$\begin{array}{l}\text { Decisão } \\
\text { unânime }\end{array}$} & \multirow[t]{2}{*}{ A, grave } & \multirow[t]{2}{*}{ Via eleita incabível. } & \multirow{2}{*}{$\begin{array}{l}\text { Interrupção de tratamento pro- } \\
\text { voca limitação da qualidade de } \\
\text { vida, risco de morte e morbida- } \\
\text { de. } \\
\text { Necessidade de uso contínuo. }\end{array}$} & \multirow[t]{2}{*}{$\begin{array}{l}\text { Incabível supor a desnecessidade } \\
\text { de medicamento conforme orien- } \\
\text { tação médica. }\end{array}$} \\
\hline & & & & & & & \\
\hline \multirow{4}{*}{ DJ6 } & \multirow{4}{*}{$\begin{array}{c}20110020069273 \\
\text { MSG }\end{array}$} & \multirow{4}{*}{ Favorável } & \multirow{4}{*}{$\begin{array}{l}\text { Decisão } \\
\text { unânime }\end{array}$} & \multirow{4}{*}{ A, grave } & $\begin{array}{l}\text { O Distrito Federal pleiteia a } \\
\text { substituição pelo fator VIII } \\
\text { plasmático. }\end{array}$ & $\begin{array}{l}\text { Interrupção de tratamento pro- } \\
\text { voca limitação da qualidade de } \\
\text { vida, risco de sequelas perma- } \\
\text { nentes, morte e morbidade. }\end{array}$ & $\begin{array}{l}\text { Dever do Estado o direito à vida e à } \\
\text { saúde (art. } 196 \text { da CF e } 207 \text { da } \\
\text { LODF). }\end{array}$ \\
\hline & & & & & $\begin{array}{l}\text { Aprovado pelos protocolos } \\
\text { clínicos oficiais). }\end{array}$ & & $\begin{array}{l}\text { Poder Público garantir acesso uni- } \\
\text { versal e igualitário. }\end{array}$ \\
\hline & & & & & $\begin{array}{l}\text { O Distrito Federal pretende } \\
\text { utilizar, após avaliação médi- } \\
\text { ca, o Concentrado de Fator } \\
\text { VIII, de origem plasmática } \\
\text { (aprovado pelos protocolos } \\
\text { clínicos oficiais). }\end{array}$ & $\begin{array}{l}\text { Medicamento similar oferece } \\
\text { risco de alergias (alergia e anafi- } \\
\text { laxia, necessitando de tratamen- } \\
\text { to hospitalar emergencial). }\end{array}$ & $\begin{array}{l}\text { A assistência à saúde sem obstácu- } \\
\text { los no acesso dos mais necessitados } \\
\text { aos tratamentos necessários ao } \\
\text { restabelecimento de suas condi- } \\
\text { ções de saúde. }\end{array}$ \\
\hline & & & & & & & $\begin{array}{l}\text { Não observância a reserva do pos- } \\
\text { sível. }\end{array}$ \\
\hline \multirow{4}{*}{ DJ7 } & \multirow{4}{*}{$\begin{array}{l}2011002 \\
024387-4\end{array}$} & \multirow{4}{*}{ Favorável } & \multirow{4}{*}{$\begin{array}{l}\text { Decisão } \\
\text { por maio- } \\
\text { ria }\end{array}$} & \multirow{4}{*}{ A, grave } & $\begin{array}{l}\text { Não previsto nos protocolos } \\
\text { clínicos do Distrito Federal. }\end{array}$ & $\begin{array}{l}\text { Medicamento similar oferece } \\
\text { risco de alergias (alergia e anafi- } \\
\text { laxia, necessitando de tratamen- } \\
\text { to hospitalar emergencial). }\end{array}$ & $\begin{array}{l}\text { Dever do Estado o direito à vida e à } \\
\text { saúde (art. } 196 \text { da CF e 204/207 da } \\
\text { LODF). }\end{array}$ \\
\hline & & & & & Alto custo. & $\begin{array}{l}\text { O fornecimento da medicação é } \\
\text { imprescindível para a manuten- } \\
\text { ção da vida do impetrante. }\end{array}$ & $\begin{array}{l}\text { Poder Público garantir acesso uni- } \\
\text { versal e igualitário. }\end{array}$ \\
\hline & & & & & & & $\begin{array}{l}\text { Cada um deve receber tratamento } \\
\text { condigno de acordo com o estado } \\
\text { atual da ciência médica, indepen- } \\
\text { dentemente de sua situação eco- } \\
\text { nômica. }\end{array}$ \\
\hline & & & & & & & $\begin{array}{l}\text { Criança de tenra idade e que neces- } \\
\text { sita do tratamento para ter uma } \\
\text { vida digna. }\end{array}$ \\
\hline
\end{tabular}




\begin{tabular}{|c|c|c|c|c|c|c|c|}
\hline \multirow{5}{*}{ DJ8 } & \multirow{5}{*}{$\begin{array}{c}2012.00 .2 .00976 \\
4-8\end{array}$} & \multirow{5}{*}{ Favorável } & \multirow{5}{*}{$\begin{array}{l}\text { Decisão } \\
\text { por maio- } \\
\text { ria }\end{array}$} & \multirow{5}{*}{ A, grave } & $\begin{array}{l}\text { Não previsto nos protocolos } \\
\text { clínicos do Distrito Federal. }\end{array}$ & $\begin{array}{l}\text { Medicamento similar oferece } \\
\text { risco de alergias (alergia e anafi- } \\
\text { laxia, necessitando de tratamen- } \\
\text { to hospitalar emergencial). }\end{array}$ & $\begin{array}{l}\text { Dever do Estado o direito à vida e à } \\
\text { saúde (art. } 196 \text { da CF e 204/207 da } \\
\text { LODF). }\end{array}$ \\
\hline & & & & & Alto custo. & $\begin{array}{l}\text { Produto não derivado de san- } \\
\text { gue/plasma humano a fim de } \\
\text { evitar a contaminação do pacien- } \\
\text { te por organismos transmitidos } \\
\text { pelo sangue humano e deriva- } \\
\text { dos, como vírus e príons (partes } \\
\text { de proteínas). }\end{array}$ & $\begin{array}{l}\text { Poder Público garantir acesso uni- } \\
\text { versal e igualitário. }\end{array}$ \\
\hline & & & & & & & $\begin{array}{l}\text { A assistência à saúde sem obstácu- } \\
\text { los no acesso dos mais necessitados } \\
\text { aos tratamentos necessários ao } \\
\text { restabelecimento de suas condi- } \\
\text { ções de saúde. }\end{array}$ \\
\hline & & & & & & & $\begin{array}{l}\text { Compete ao DF prestação de assis- } \\
\text { tência farmacêutica e a garantia de } \\
\text { acesso da população aos medica- } \\
\text { mentos necessários. }\end{array}$ \\
\hline & & & & & & & $\begin{array}{l}\text { Medicamento similar oferece risco } \\
\text { de danos irreversíveis à saúde do } \\
\text { requerente. }\end{array}$ \\
\hline \multirow{4}{*}{ DJ9 } & \multirow{4}{*}{$\begin{array}{c}2012.00 .2 .00976 \\
4-8\end{array}$} & \multirow{4}{*}{ Favorável } & \multirow{4}{*}{$\begin{array}{l}\text { Decisão } \\
\text { por maio- } \\
\text { ria }\end{array}$} & \multirow{4}{*}{ A, grave } & $\begin{array}{l}\text { Não previsto nos protocolos } \\
\text { clínicos do Distrito Federal. }\end{array}$ & $\begin{array}{l}\text { Medicamento similar oferece } \\
\text { risco de alergias (alergia e anafi- } \\
\text { laxia, necessitando de tratamen- } \\
\text { to hospitalar emergencial). }\end{array}$ & $\begin{array}{l}\text { Dever do Estado o direito à vida e à } \\
\text { saúde (art. } 196 \text { da CF e } 204 / 207 \text { da } \\
\text { LODF). }\end{array}$ \\
\hline & & & & & Alto custo. & & $\begin{array}{l}\text { Poder Público garantir acesso uni- } \\
\text { versal e igualitário. }\end{array}$ \\
\hline & & & & & & $\begin{array}{l}\text { Medicamento oferecido pelo SUS } \\
\text { tem risco de contaminação }\end{array}$ & $\begin{array}{l}\text { Compete ao DF prestação de assis- } \\
\text { tência farmacêutica e a garantia de } \\
\text { acesso da população aos medica- } \\
\text { mentos necessários. }\end{array}$ \\
\hline & & & & & & $\begin{array}{l}\text { Melhoria na qualidade de vida } \\
\text { com o medicamento pleiteado }\end{array}$ & $\begin{array}{l}\text { O acesso ao medicamento garante } \\
\text { preservação da sua vida. }\end{array}$ \\
\hline
\end{tabular}




\begin{tabular}{|c|c|c|c|c|c|c|c|}
\hline & & & & & & & $\begin{array}{l}\text { Manutenção da eficácia e integri- } \\
\text { dade de direitos individuais e/ou } \\
\text { coletivos. }\end{array}$ \\
\hline \multirow{6}{*}{ DJ10 } & \multirow{6}{*}{$\begin{array}{c}20120020173216 \\
\text { MSG }\end{array}$} & \multirow{6}{*}{ Favorável } & \multirow{6}{*}{$\begin{array}{l}\text { Decisão } \\
\text { unânime }\end{array}$} & \multirow{6}{*}{ A, grave } & Não apresentou argumentos & $\begin{array}{l}\text { Interrupção de tratamento pro- } \\
\text { voca limitação da qualidade de } \\
\text { vida, risco de morte e morbida- } \\
\text { de. }\end{array}$ & $\begin{array}{l}\text { Dever do Estado o direito à vida e à } \\
\text { saúde (art. } 196 \text { da CF e 204/207 da } \\
\text { LODF). }\end{array}$ \\
\hline & & & & & & & $\begin{array}{l}\text { A assistência à saúde sem obstácu- } \\
\text { los no acesso dos mais necessitados } \\
\text { aos tratamentos necessários ao } \\
\text { restabelecimento de suas condi- } \\
\text { ções de saúde. }\end{array}$ \\
\hline & & & & & & & $\begin{array}{l}\text { Prevenir hemorragias e evitando as } \\
\text { complicações. }\end{array}$ \\
\hline & & & & & & & $\begin{array}{l}\text { Fornecimento de medicamentos } \\
\text { e/ou tratamentos de saúde devem } \\
\text { ser tomadas com cautela, ampa- } \\
\text { rando-se na proporcionalidade } \\
\text { (impacto nas políticas públicas/ } \\
\text { saúde). }\end{array}$ \\
\hline & & & & & & & $\begin{array}{l}\text { Técnica da ponderação, observa-se } \\
\text { que a medida pretendida é neces- } \\
\text { sária e adequada, consoante relató- } \\
\text { rio médico. }\end{array}$ \\
\hline & & & & & & & $\begin{array}{l}\text { Oferta de medicamento na quanti- } \\
\text { dade indicada pelo médico diante } \\
\text { de receita médica. }\end{array}$ \\
\hline \multirow{3}{*}{ DJ11 } & \multirow{3}{*}{$\begin{array}{l}20140020166863 \\
\text { AGI }\end{array}$} & \multirow{3}{*}{ Favorável } & \multirow{3}{*}{$\begin{array}{l}\text { Decisão } \\
\text { unânime }\end{array}$} & \multirow{3}{*}{ A, grave } & $\begin{array}{l}\text { Não previsto nos protocolos } \\
\text { clínicos do Distrito Federal. }\end{array}$ & $\begin{array}{l}\text { Hemofilia A grave e crônica em } \\
\text { tratamento no DF desde os } 14 \\
\text { anos. }\end{array}$ & $\begin{array}{l}\text { Dever do Estado o direito à vida e à } \\
\text { saúde (art. } 196 \text { da CF e 204/207 da } \\
\text { LODF). }\end{array}$ \\
\hline & & & & & $\begin{array}{l}\text { violação do princípio de iso- } \\
\text { nomia/igualdade e impessoa- } \\
\text { lidade }\end{array}$ & $\begin{array}{l}\text { reações alérgicas com tratamen- } \\
\text { to oferecido pelo SUS }\end{array}$ & $\begin{array}{l}\text { Medicamento prescrito é autoriza- } \\
\text { do pelo ANVISA. }\end{array}$ \\
\hline & & & & & & & $\begin{array}{l}\text { Outro não foi indicado com igual } \\
\text { eficácia. Comprovação da necessi- } \\
\text { dade ao paciente }\end{array}$ \\
\hline
\end{tabular}




\begin{tabular}{|c|c|c|c|c|c|c|c|}
\hline \multirow{7}{*}{ DJ12 } & \multirow{7}{*}{$\begin{array}{c}20160020226574 \\
\text { MSG }\end{array}$} & \multirow{7}{*}{ Favorável } & \multirow{7}{*}{$\begin{array}{l}\text { Decisão } \\
\text { unânime }\end{array}$} & \multirow{7}{*}{$B$, grave } & $\begin{array}{l}\text { Não previsto nos protocolos } \\
\text { clínicos do Distrito Federal. }\end{array}$ & $\begin{array}{l}\text { Medicamento similar oferece } \\
\text { risco de alergias (alergia e anafi- } \\
\text { laxia, necessitando de tratamen- } \\
\text { to hospitalar emergencial). }\end{array}$ & $\begin{array}{l}\text { Os pacientes hemofílicos recebam } \\
\text { tratamento conforme o Protocolo } \\
\text { do Ministério da Saúde, ressalvada } \\
\text { a necessidade de terapia diversa, } \\
\text { desde que comprovada por junta } \\
\text { médica oficial" (Susp. Liminar STF } \\
\text { 1019). Para o paciente em questão, } \\
\text { a necessidade de terapia diversa foi } \\
\text { devidamente comprovada. }\end{array}$ \\
\hline & & & & & $\begin{array}{l}\text { Não há prova de necessidade } \\
\text { de tratamento diferenciado }\end{array}$ & $\begin{array}{l}\text { Medicamento similar oferece } \\
\text { risco de contaminação por pató- } \\
\text { genos, que podem desencadear } \\
\text { outras enfermidades conhecidas } \\
\text { e não conhecidas, agravadas por } \\
\text { mutações genéticas, sendo des- } \\
\text { conhecido o grau de virulência e } \\
\text { letalidade. }\end{array}$ & $\begin{array}{l}\text { Comprovação de maior eficácia e } \\
\text { mais adequada evidência científica. } \\
\text { Fator recombinante tem capacida- } \\
\text { de prolongada. }\end{array}$ \\
\hline & & & & & $\begin{array}{l}\text { Não há notícias de contami- } \\
\text { nação de pacientes com me- } \\
\text { dicação ofertada pelo SUS }\end{array}$ & $\begin{array}{l}\text { Medicamento pleiteado evita } \\
\text { sangramentos visíveis e subclíni- } \\
\text { cos }\end{array}$ & $\begin{array}{l}\text { Dever do Estado o direito à vida e à } \\
\text { saúde (art. } 196 \text { da CF e } 204 / 207 \text { da } \\
\text { LODF). }\end{array}$ \\
\hline & & & & & & & $\begin{array}{l}\text { Observância ao princípio a dignida- } \\
\text { de humana. }\end{array}$ \\
\hline & & & & & & $\begin{array}{l}\text { Protocolo do SUS não previne } \\
\text { sangramento }\end{array}$ & $\begin{array}{l}\text { Em um dos cenários trazidos pela } \\
\text { CONITEC é mais vantajoso para o } \\
\text { Estado e para o pacien- } \\
\text { te/impetrante adquirir o medica- } \\
\text { mento sintético pleiteado neste } \\
\text { mandado de segurança. }\end{array}$ \\
\hline & & & & & & $\begin{array}{l}\text { Prevenir hemorragias e evitando } \\
\text { as complicações. }\end{array}$ & $\begin{array}{l}\text { O tratamento fornecido pelo Proto- } \\
\text { colo Clínico do Ministério da Saúde } \\
\text { não é eficaz no seu caso. }\end{array}$ \\
\hline & & & & & & & $\begin{array}{l}\text { medicamento oferecido pelo SUS } \\
\text { tem risco de contaminação }\end{array}$ \\
\hline DJ13 & $\begin{array}{c}20160110252652 \\
\text { APC }\end{array}$ & Desfavorável & $\begin{array}{l}\text { Decisão } \\
\text { unânime }\end{array}$ & B, severa & $\begin{array}{l}\text { Sem embasamento científico } \\
\text { ou estatístico da possibilida- } \\
\text { de de contaminação nos }\end{array}$ & $\begin{array}{l}\text { O tratamento que vinha sendo } \\
\text { utilizado no autor trouxe melho- } \\
\text { ras significativas nas sequelas, }\end{array}$ & $\begin{array}{l}\text { Não há razão para mudança de } \\
\text { tratamento. }\end{array}$ \\
\hline
\end{tabular}




\begin{tabular}{|c|c|c|c|c|c|c|c|}
\hline & & & & & $\begin{array}{l}\text { medicamentos de fator plas- } \\
\text { mático. }\end{array}$ & $\begin{array}{l}\text { Ihe permitindo adequado conví- } \\
\text { vio em sociedade. }\end{array}$ & \\
\hline & & & & & $\begin{array}{l}\text { Não há no momento estudos } \\
\text { que provem diferença de } \\
\text { eficácia entre os medicamen- } \\
\text { tos IX plasmático, IX recom- } \\
\text { binante e IX recombinante de } \\
\text { longa duração. }\end{array}$ & $\begin{array}{l}\text { O autor apresentou "melhoras } \\
\text { impressionantes" decorrentes do } \\
\text { tratamento através do medica- } \\
\text { mento fornecido pelo SUS. }\end{array}$ & $\begin{array}{l}\text { Medicamento oferecido pelo SUS } \\
\text { demonstra a mesma eficácia do } \\
\text { pleiteado }\end{array}$ \\
\hline & & & & & $\begin{array}{l}\text { Não havia diferença de eficá- } \\
\text { cia entre IX recombinante de } \\
\text { longa duração e plasmático, } \\
\text { que é oferecido pelo SUS, } \\
\text { pois o fabricante não de- } \\
\text { monstrou a superioridade de } \\
\text { eficácia desse medicamento }\end{array}$ & & \\
\hline & & & & & $\begin{array}{l}\text { Medicamentos recombinante } \\
\text { e plasmático são eficazes, } \\
\text { muito seguros, não existindo } \\
\text { relatos de contaminação pelo } \\
\text { uso destes desde } 1997 \text {. }\end{array}$ & & \\
\hline & & & & & $\begin{array}{l}\text { Não há comprovação de } \\
\text { ineficácia no tratamento } \\
\text { atual. }\end{array}$ & & \\
\hline \multirow{3}{*}{ DJ14 } & \multirow{3}{*}{$\begin{array}{c}0021948- \\
66.2010 .4 .01 .340 \\
0\end{array}$} & \multirow{3}{*}{ Favorável } & \multirow{3}{*}{$\begin{array}{l}\text { Decisão } \\
\text { unânime }\end{array}$} & \multirow{3}{*}{ A, grave } & $\begin{array}{l}\text { Impossibilidade de fornecer } \\
\text { qualquer tratamento a qual- } \\
\text { quer custo. }\end{array}$ & $\begin{array}{l}\text { Demonstram de forma suficiente } \\
\text { a eficácia da medicação pleitea- } \\
\text { da para o quadro clínico do paci- } \\
\text { ente. }\end{array}$ & $\begin{array}{l}\text { Dever do Estado o direito à vida e à } \\
\text { saúde (art. } 196 \text { da CF e 204/207 da } \\
\text { LODF). }\end{array}$ \\
\hline & & & & & Princípio do seguro prudente. & $\begin{array}{l}\text { Medicamento similar oferece } \\
\text { risco de alergias (alergia e anafi- } \\
\text { laxia, necessitando de tratamen- } \\
\text { to hospitalar emergencial). }\end{array}$ & Imperativo de solidariedade social. \\
\hline & & & & & $\begin{array}{l}\text { Impossibilidade de forneci- } \\
\text { mento de medicamentos não } \\
\text { padronizados. }\end{array}$ & $\begin{array}{l}\text { Medicamento similar oferece } \\
\text { risco de contaminação por pató- } \\
\text { genos, que podem desencadear } \\
\text { outras enfermidades conhecidas } \\
\text { e não conhecidas, agravadas por }\end{array}$ & $\begin{array}{l}\text { A assistência à saúde sem obstácu- } \\
\text { los no acesso dos mais necessitados } \\
\text { aos tratamentos necessários ao } \\
\text { restabelecimento de suas condi- } \\
\text { ções de saúde. }\end{array}$ \\
\hline
\end{tabular}




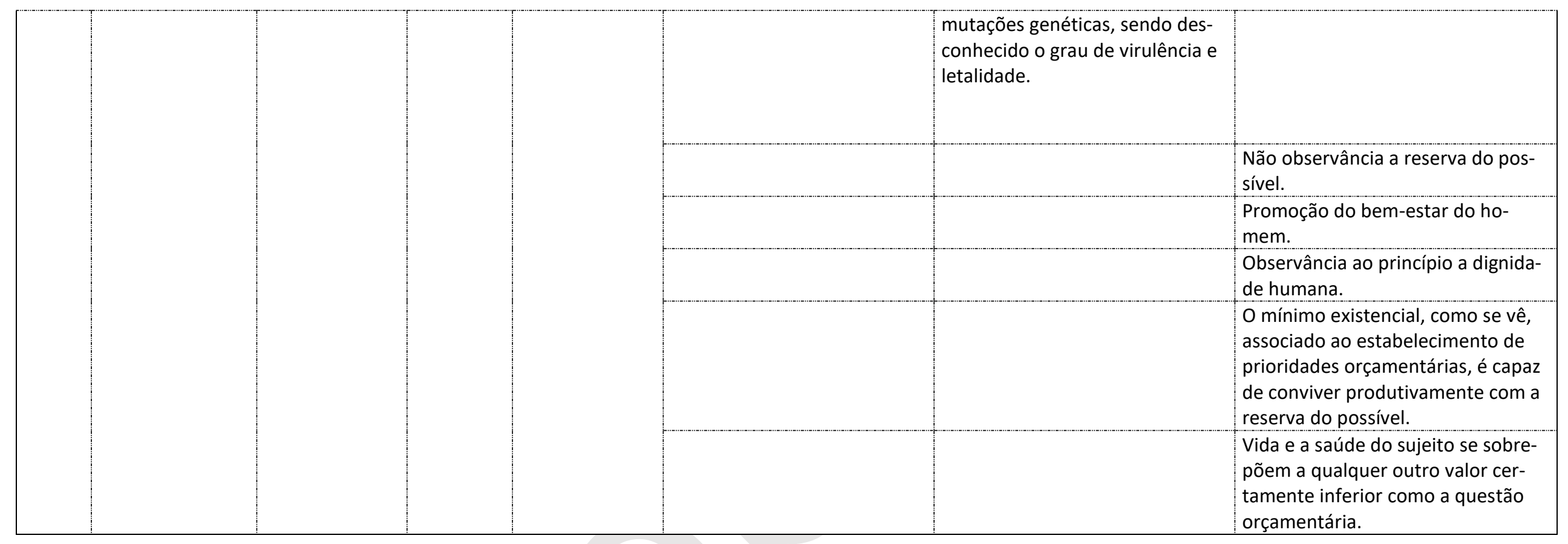

